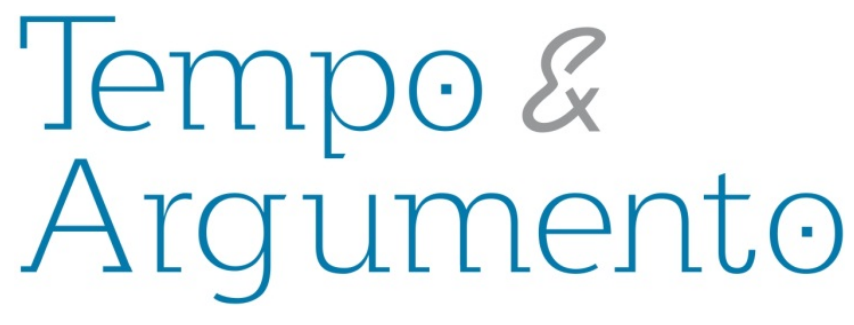

\title{
A teia, a tela e o tempo: internet e história do tempo presente
}

\begin{abstract}
Resumo
O enfoque deste artigo será uma apresentação da pesquisa em história e Internet, pensando esta como um documento dentro dos estudos da História da Cultura Escrita e da Leitura. Ao propiciar novas formas de ler e escrever na contemporaneidade, a Internet perpassa por várias modalidades tais como os comunicadores instantâneos (MIRC e MSN), as redes sociais (Orkut, Facebook), notícias, vídeos entre outros. Com destaque a novos mecanismos de sociabilidade que funcionam como mediadores para interação entre grupos que utilizam as redes sociais. Os documentos são abordados na perspectiva da História do Tempo Presente, que possibilita pensarmos um passadopresente, em que os recuos e aproximações com as fontes são possibilitados pelas escolhas do historiador que problematiza este Presente
\end{abstract}

Palavras-chave: História; Escrita; Leitura; Redes de Relações Sociais.

\author{
Pedro Eurico Rodrigues \\ Doutorando em História Social pela \\ Universidade de São Paulo - USP. Professor \\ substituto do Departamento de História da \\ Universidade Federal de \\ Santa Catarina - UFSC. \\ Brasil \\ pedro.eurico.rodrigues@gmail.com
}

\section{Para citar este artigo: \\ RODRIGUES, Pedro Eurico. A teia, a tela e o tempo: internet e história do tempo presente. Revista Tempo e Argumento, Florianópolis, v. 6, n. 12, p. 131 -150, mai./ago. 2014.}

DOI: $10.5965 / 2175180306122014131$

http://dx.doi.org/10.5965/2175180306122014131 


\begin{abstract}
The focus of this article will be a presentation of research in history and the Internet, thinking this as a document within the study of the History of Writing and Reading Culture. By providing new ways of reading and writing in contemporary Internet permeates various modalities such as instant messaging ( MIRC and MSN ), the social networks ( Orkut , Facebook ), news, videos and more. Highlighting the new mechanisms of sociability that act as mediators for interaction between groups using social networks. The documents are addressed in the perspective of history Present Time, enabling think a past-present, where setbacks and approaches to sources are made possible by the choices the historian who discusses this present.
\end{abstract}

Keywords: History; Writing; Reading; Social networks. 
Criar meu web site/ Fazer minha home-page/ Com quantos gigabytes/ Se faz uma jangada/ Um barco que veleje/ Que veleje nesse informar/ Que aproveite a vazante da infomarél Que leve um oriki do meu orixál Ao porto de um disquete de um micro em Taipél Um barco que veleje nesse infomar/ Que aproveite a vazante da infomarél Que leve meu email até Calcutá/ Depois de um hot-link/ Num site de Helsinque/ Para abastecer/ Eu quero entrar na rede/ Promover um debate/ Juntar via Internet/ Um grupo de tietes de Connecticut/ De Connecticut de acessar/ O chefe da Mac Milícia de Milão/ Um hacker mafioso acaba de soltar/ Um vírus para atacar os programas no Japão/ Eu quero entrar na rede para contatar/Os lares do Nepal, os bares do Gabão/ Que o chefe da polícia carioca avisa pelo celular/ Que lá na praça Onze tem um videopôquer para se jogar... ${ }^{1}$

Homepage, gigabytes, micro (computador), e-mail, hot-link, Internet, hacker, vírus e celular ${ }^{2}$ são palavras que usualmente não frequentavam a escrita da história. Provindas de uma nova sensibilidade global, essas novas nomenclaturas interferiram e continuam interferindo - direta e indiretamente - no cotidiano de milhares de pessoas. Especificamente no Brasil, acessar a Internet tem sido cada vez mais comum, seja pela facilitação para as compras de microcomputadores, no acesso às lan houses e aos cibercafés (outras nomenclaturas dicionarizadas), ou nos laboratórios de informática em algumas escolas, universidades, institutos técnicos públicos e bibliotecas do país, pensando no acesso de forma direta. Há também aqueles que são afetados indiretamente: tanto os que não tiveram acesso à cultura escrita ${ }^{3}$ na escola, bem como os

GIL, Gilberto. Pela Internet In: Quanta. Warner Music, 1997. (Grifos do autor)

Cabe aqui resaltar que estas palavras, com exceção de hotlink, foram incorporadas no Dicionário Aurélio 2010, e serão usadas aqui conforme a sua nova escrita dicionarizada.

3 O termo cultura escrita refere-se às diferentes análises das funções, usos e práticas relacionadas com o escrito formas do escrito, ou seja, dos atos de ecrita e leitura. Um estudioso do tema é o historiador espanhol António Castillo Gómez: que faz estudos sobre sua historicidade e para quem "[...] la historia de la cultura escrita se define por el alcance de sus enunciados y por la interdisciplinaridad de un método que debe buscar las alianzas com cuantos saberes tienen su objeto en el estudio de la escritura. [...] cualquiera que sea su concreta materialidad - del documento oficial a la carta privada - o soporte - de la tablilla de arcilla a la pantalla electrónica - Lo que pretende es desvelar cada uno de los lugares, maneras y gestos que históricamente han regido la relaciones entre el mundo del texto y el mundo de los 
que não têm tempo e/ou dinheiro para acompanhar todas as novidades. Estes últimos, por sua vez, estão sendo bombardeados pelas mídias com propagandas sobre Internet, ou seja, mesmo quem não está no on-line ${ }^{4}$ efetivamente é colocado neste turbilhão informacional causado pelo "tsunami" da "infomaré", nas palavras do compositor Gilberto Gil, na epígrafe que abre este artgo.

Esses aspectos mudaram a forma de lidar com a informação, com os relacionamentos, com a escrita, com a leitura e com a educação, bem como com a realização de compras e a necessidade de se comunicar. Essa onda de mudanças está posta e efetivamente atinge boa parte da população brasileira e mundial, principalmente nos últimos quinze anos, em que pelo menos uma geração já tem familiaridade com essas nomenclaturas que estão naturalizadas e internalizadas em suas vidas cotidianas. $\mathrm{Na}$ música, o indivíduo passa a estar em vários lugares ao mesmo tempo, como: Taípe, Calcutá, Helsinque, Connecticut, Milão, Japão, Nepal, Gabão, Praça Onze, mostrando que essa "globalização imaginada" (GARCÍA CANCLINI, 2007) está para além das transações na bolsa de valores e viagens/migrações internacionais. O indivíduo pode, agora, experimentar um outro tipo de viagem, através da tela do seu computador pessoal, sem sair de casa, podendo ler e escrever, além de interagir com outras pessoas do seu país e do mundo. Este indivíduo que ficou conhecido como internauta - ou o navegador desse “infomar”, como propõe a música - multiplicou-se tão rápido, paralelamente ao crescimento da teia (a web). É sobre esses desbravadores/as e os seus rastros, nos muitos mares cibernéticos, que trata esse trabalho. Como todo desbravador/a de um novo mundo, encontram-se percalços dos mais infindáveis.

Este artigo pretende abordar o impacto da Internet no que tangencia as sociabilidades, aproximando as metodologias de história do tempo presente com a rede mundial de computadores, trazendo também algumas questões sobre ler e escrever na contemporaneidade. $\mathrm{O}$ artigo será dividido em três partes: A Teia, que fará um discussão sobre Intertnet e a velocidade de sua mudanças; A Tela, que irá apresentar brevemente as formas de ler e escrever dos internautas; e O Tempo, que buscará discutir a metodologia da História do Tempo Presente com o objeto proposto. 


\section{A Teia}

Nos entrelaços da contemporaneidade, temos na teia, que se configura a Internet, mais uma possibilidade de se estender no tempo e no espaço, de estar junto. Pensar nestes emaranhados que se põem no presente e que vão desde de situações cotidianas, que nos fazem indagar o objeto, até a busca por compreensão em diálogo com outros autores.

Situações do dia a dia sinalizam para esta presença da informática. Por exemplo: no ano de 2009, em uma turma de $5^{\circ}$ ano (alunos de nove e dez anos) da Escola Autonomia em Florianópolis, na qual eu era professor da disciplina do projeto transdisciplinar de Rádio Escola, um dos temas de programas escolhidos pelos alunos foi a Internet e as novidades que ela trazia, como jogos, vídeos e suas redes sociais. Procurei relatar a eles como era a Internet que eu conheci, que vi mudar em tão pouco tempo: era a Internet discada ${ }^{5}$, em que se esperava às vezes até uma hora para ficarmos on-line e na qual as imagens demoravam muito para abrir. O que eu ouvi foram várias gargalhadas e, no meio delas, uma pergunta: “Não existia banda larga, professor?”. A perplexidade dos alunos com a resposta negativa me fez perceber o quanto era considerável para história tentar entender a emergência dessas práticas em que o poder da tecnologia além de propiciar novas sensibilidades para estas e outras gerações, evidencia uma certa redução da vida ao imediatismo do presente o que reverbera na aceleração da história, como nos lembra Pierre Nora (1993).

Atualmente, é possível afirmar que a presença da Internet é visceral nas nossas vidas. Hoje, o Estado da Arte que fazemos para iniciar uma pesquisa não consiste em apenas percorrer incansavelmente corredores de bibliotecas e estantes de livros. Inevitavelmente, a primeira atitude que é tomada ao se pensar um novo tema de pesquisa é buscá-lo na página do Google ${ }^{6}$, ainda que os resultados possam surpreender. No caso em estudo, ao digitar as palavras "História da Internet" no campo de busca do site, com o desejo de conferir se algum historiador aventurou-se a desfiar a teia, tive uma

5 Conhecida também como conexão dial-up, que é uma conexão comutada à Internet, realizada por meio de um modem analógico e uma linha da rede de telefonia fixa, que requer que o modem disque um número telefônico para realizar a conexão (Pesquisa sobre o Uso das Tecnologias da Informação e da Comunicação no Brasil: TIC Domicílios e TIC Empresas, 2008, p. 449).

6 Site de busca www.google.com 
são uma característica ímpar do texto eletrônico. As informações disponíveis mostravam os outros links que o site de busca me apresenta: eram provindos de blogs comentando superficialmente o assunto, bem como sites de notícias dizendo que a Internet estava completando 40 anos.

Entretanto, já é possível encontrar considerável número de estudos que tematizam a teia, do ponto de vista da História e, nesse sentido, há trabalhos relevantes que foram consultados. Um dos mais importantes foi proposto pelo historiador uruguaio Juan Andrés Bresciano, que escreveu o livro "La Historiografía en El amanecer de La cultura digital”, em 2010. O autor tem se debruçado sobre o tema há alguns anos. O livro trata dos novos documentos no formato digital, bem como metodologias que envolvem estas novas questões. Segundo ele, o crescimento das fontes digitais da segunda metade do século $X X$ aos nossos dias foi tão grande que tem afetado as formas de se relacionar com o texto impresso, processo que tem afetado também o campo historiográfico:

Este proceso afecta a la Historiografía en tres planos diferentes: (i) Supone en sí mismo un fenómeno a estudiar, ya que se trata de un proceso de transformación mundial de particular relevancia. (ii) Aporta un caudal inusitado de fuentes para el conocimiento histórico, por el volumen y la diversidad de registros que produce. (iii) Modifica el modo en que se obtiene la información y se genera saber. Dado que la Ciencia Histórica no es una excepción, también afecta a las prácticas de investigación sobre el pasado. (BRESCIANO, 2010, p. 13)

A partir destes três pontos propostos pelo autor, pode-se notar que a prática historiográfica ganha novas perspectivas, pois aprender a lidar com estes novos documentos possibilita novos olhares sobre o passado. Estas questões sobre os documentos digitais, na opinião do autor, enfrentam problemas, os quais ele destaca em três pontos:

7 Chama-se "wiki" palavra que no idioma havaiano significa "rápido", a mais simples e flexível ferramenta de colaboração pela Internet. A wiki mais famosa atualmente é a wikipedia, enciclopédia livre da Internet construída por milhões de usuários (HANNUD, 2009, p. 57-58).

8 Links são elos, na forma de endereços eletrônicos, presentes nos sites, demonstrando a possibilidade de acesso a variados sites a partir de um só, que disponibiliza tantos outros endereços em suas páginas. 
(i) el acceso a las fuentes y las formas actuales de su difusión masiva; (ii)

la conservación de documentos que por la naturaleza de su soporte tienden a descartarse rápidamente, una vez que han cumplido su función; (iii) el desarrollo de nuevos repositorios, concebidos específicamente para custodiarlos. (BRESCIANO, 2010, p. 18)

Assim, as questões levantadas por este autor ajudaram a pensar na forma de tratamento com tais documentos que representam um novo desafio para a historiografia.

Uma certa carência de obras que associam Internet e História, faz com que se procure um salutar diálogo com uma série de teóricos de outras áreas que já se debruçaram sobre o tema, como o filósofo francês Pierre Levy, que discute o virtual (1996) e também cunhou o termo Cibercultura (2010), e que estuda e escreve sobre as novas possibilidades de interação humana no meio virtual, da arte às relações pessoais.

Meu otimismo, contudo, não promete que a Internet resolverá, em um passe de mágica, todos os problemas culturais e sociais do planeta. Consiste apenas em dois fatos. Em primeiro lugar, que o crescimento do ciberespaço resulta de um movimento internacional de jovens ávidos para experimentar, coletivamente, formas de comunicação diferentes daquelas que as mídias clássicas nos propõem. Em segundo lugar, que estamos vivendo a abertura de um novo espaço de comunicação, e cabe apenas a nós explorar as potencialidades mais produtivas deste espaço nos planos econômico, político, cultural e humano. (LEVY, 2010, p. 11)

De igual maneira, o sociólogo espanhol Manuel Castells discute as várias interações da web (teia) mostrando a entrada da Internet como definidora para as novas relações interpessoais e do mundo dos negócios, apontando direções para o estudo desse tema transversal, quando fala que:

a Internet está sendo usada para redefinir as relações de família numa sociedade em que as pessoas estão experimentando novas formações familiares. Mostra como o e-mail permitiu a muitos realizar o que chama de "famílias de escolha", incorporando à vida cotidiana da família estranhos conhecidos via Internet, ou com quem o contato foi desenvolvido ou enriquecido por uma interação baseada na Internet durante um período. Assim, a prática do individualismo em rede pode estar redefinindo as fronteiras e o significado de instituições tradicionais de sociabilidade, como a família. (CASTELLS, 2003, p. 110)

Castells é categórico em afirmar, ainda, que os usuários da Internet estão "reconstruindo" o padrão de interação, com a ajuda de novos recursos tecnológicos, para criar uma nova forma de sociedade: a "sociedade em rede". 
Asa Briggs e Peter Burke, historiadores, escreveram o livro "História Social da Mídia: de Gutenberg à Internet" (2006), e dedicam espaço em seus capítulos finais para problematizar as mídias do século XXI. Ao abordarem a Internet, os autores dão uma perspectiva das Grandes Corporações como IBM, Microsoft, Yahoo e Google, pondo de lado os rastros que os usuários destas corporações deixam no meio virtual.

Mais recentemente, Robert Darnton (2010) argumenta sobre a questão do Google Search Book, projeto da empresa Google, que pretende digitalizar os acervos de grandes bibliotecas dos Estados Unidos e passa a lucrar através das obras raras cobrando pelos seus acessos, porém disponibilizaria a outra parte do acervo on-line, deixando que o leitor muitas vezes até faça a impressão de certos textos. Esta prática gerou grandes embates judiciais, pois muitas das obras que podiam ser visitadas estavam abrigadas pela lei do copyright, protegendo os seus autores. Para além das disputas judiciais, o autor aponta o monopólio da empresa com um bem público e enxerga isso de forma negativa, pois estes acervos passariam a estar apenas na mão de uma única empresa, que controlaria o futuro destes livros.

Ora, a História da Internet seria algo muito abrangente para um historiador poder se debruçar e, certamente, essa história viria com recortes - tanto temporais, como temáticos e teóricos, pois é necessário romper com a presunção de que um novo recorte teórico seja capaz de esgotar questões que envolvem experiêncas diversas. Pensando dessa forma, comecei a me perguntar de que forma a história poderia se apropriar da Internet a fim de construir/ler um passado recente? Que documetos poderiam dar tais respostas? Ao começar a estranhar o que me era comum, deparei-me com longos comentários no Twitter ${ }^{9}$ sobre a notícia daquele momento, em 2009: o casamento de dois blogueiros, cuja celebração matrimonial foi patrocinada pela Secretaria de Turismo de Porto de Galinhas (PE), o que gerou comentários favoráveis e contrários à prática. Esse episódio ajudou-me a pensar em diferentes formas de convivência social que, pela afirmação de afinidades e interesses em comum constroem novas sociabilidades. Nesse caso, a Internet havia proporcionado no decorrer da última década, encontros, casamentos, namoros e amizades surgiram apenas "por estar junto" através do contato

9 Site de microblogs www.twitter.com 
tela a tela. Esta constatação contribuiu para esclarecer meu tema: pesquisar as sociabilidades $^{10}$ da Internet, o romper de barreiras do virtual, pelo simples fato de (re)conhecer o outro, o qual antes estava distante e cuja proximidade só seria alcançada pelo computador. A partir dessa visibilidade fui instigado a analisar as produções de si (GOMES, 2004) em uma rede social que se popularizou no Brasil no ano de 2005: o Orkut $^{11}$.

A Tela

Com o advento dos computadores domésticos, a população em geral experimentou uma nova forma de ler e escrever, e, com a Internet, esta possibilidade se ampliou, o que Roger Chartier (2002) chama de texto eletrônico. Percebe-se a mudança nesta modalidade a partir de três pontos: sendo o primeiro deles relativo à escrita do texto, o segundo referente à escrita diretamente na biblioteca, e o terceiro referente à construção de uma biblioteca universal, pensando na rede mundial de computadores como um grande acervo de informações, que dependem das ações dos internautas.

Estudar a trajetória de indivíduos na Internet é como correr contra o tempo acelerado, ao tempo em que se vai aos documentos, coleta-se no dia seguinte e eles (podem) já não estar dispostos. O sentimento é como se estivesse na cena clássica do filme "Indiana Jones e os caçadores da arca perdida", em que se corre com uma bola que destrói tudo por onde se passa os olhos. Obviamente, a bola segue um caminho linear, na Internet os documentos se perdem, por vontade ou não do indivíduo que os

10 Concordo com a definição de Gisele Martins Venâncio (2002, p. 9) para quem o termo sociabilidade pode ser entendido "como uma tendência natural para a vida em sociedade. E considerado sociável aquele indivíduo que é naturalmente disposto a procurar a sociedade, que mantém uma vida social". Igualmente, inspirado em Norbert Elias considera-se a sociabilidade como experiências compartilhadas de maneiras de ser

e de agir, que nascem da poderosa dinâmica de atividades coletivas que se entrelaçam (...) como produto e alavanca no desenvolvimento do proceso social (ELIAS,1993. p.235).

${ }^{11}$ Em 6 de julho de 2014, com o Título "Adeus Orkut", a Rede Social da empresa Google manda uma mensagem aos seus usuários via e-mail: "Após dez anos de conversas e conexões sociais on-line, nós decidimos que é hora de começar a nos despedir do Orkut. Ao longo da última década, YouTube, Blogger e Google+ decolaram, com comunidades surgindo em todos os cantos do mundo. $O$ crescimento dessas comunidades ultrapassou o do Orkut e, por isso, decidimos concentrar nossas energias e recursos para tornar essas outras plataformas sociais ainda mais incríveis para todos os usuários.O Orkut não estará mais disponível após o dia 30 de Setembro de 2014. Até lá vamos manter o Orkut no ar, sem grandes mudanças, para que você possa lidar com a transição." 
disponibilizou. Um dia, olha-se um perfil; no outro, ele já foi removido. Principalmente ao olhar para o Orkut, rede social da Internet que vem perdendo cada vez mais espaço para outros sites do mesmo gênero. Chaveau e Tétart (1999, p. 33) mostram este envolvimento entre o historiador e seu tempo, que muda com a própria disciplina:

\begin{abstract}
A presença do historiador em seu tempo evolui, portanto, em função da própria história. Não há nada de novo nisso. Em compensação, a evolução da relação com o acontecimento, a mutação dos engajamentos ou não-engajamentos intelectuais e políticos marcam uma ruptura com as gerações precedentes de historiadores. O contexto não é mais o mesmo. Isso explica, talvez, o desejo de neutralidade e de recolhimento cada vez mais marcado das novas gerações: recolhimento, neutralidade que se traduzem frequentemente em termos de pessimismo, de desinteresse ou de resignação, mas que, cientificamente, seriam os frutos do encontro entre lições epistemológicas da história do presente e a evolução do contexto histórico e da percepção imediata da história.
\end{abstract}

O que parecem indagar os historiadores é o suporte em que os documentos são guardados. Comumente, estes se encontram em arquivos, acervos pessoais e bibliotecas, ou seja, em locais físicos, ao contrário da Internet, em que os documentos são guardados em local virtual. Se perguntarmos aos documentos do primeiro grupo sobre a questão da sociabilidade na Internet na primeira década do século XXI, obter-se-iam poucas informações, geralmente através do registro da imprensa nessa década, fotos ou diários pessoais - as "escritas de dentro" (CUNHA, 2009, p. 258). Desta forma, haveria lacunas para construir uma narrativa capaz de contemplar, por exemplo, o olhar daqueles que participaram do processo. Ao incluir a Internet como documento, pode-se olhar para outras questões ao se verificar as redes sociais e os blogues. Estas podem ser consideradas "escritas de fora" ${ }^{12}$ (CUNHA, 2009, p. 258), auxiliando para que a narrativa histórica faça um desenho mais vívido desse passado, como nos coloca Albuquerque Jr. (2007, p. 64):

Não podemos fugir do limite imposto pelo nosso arquivo. Só podemos historicizar aquilo que deixou rastros de sua produção pelo homem, em dado momento e espaço. Mas desaparecem as fontes privilegiadas da

\footnotetext{
Maria Teresa Santos Cunha (2009) entende por “escritas de fora" desde os diários pessoais, como blogues, fotologs, até os perfis de redes sociais como Orkut, Myspace, Facebook. Todas estas escritas visam olhares alheios por se tornarem públicas ao estarem expostas na rede.
} 
História, ou aspectos de que o historiador não poderia se ocupar e tudo se torna historicizável e fonte de historicidade.

Ao problematizar a Internet como fonte para a história, lembrando que somente a sua parte escrita será analisada, pode-se recorrer aos aportes teóricos da cultura escrita propostos por Antonio Castillo Goméz (2002) e Roger Chartier, que pretendem dar a conhecer as relações entre o mundo do texto e o mundo dos seus usuários, no qual são fixados os "traços do passado, a lembrança dos mortos, ou a glória dos vivos" (CHARTIER, 2007, p. 9).

A "História da Cultura Escrita e da Leitura" tem como proposta analisar as produções escritas deixadas no passado, desde livros aos diários, dos panfletos à imprensa, dos grafites ao hipertexto, de cunho ordinário ou extraordinário, cada qual em seu tempo e espaço. Este campo busca analisar as mudanças dos hábitos de leitura e dos modos de ler e de escrever, bem como os suportes destas escritas e como as tais são fabricadas. Dentre os autores que trabalham a partir destes aportes teóricos, está o historiador francês Roger Chartier. Esse autor possui inúmeros livros na área, os quais versam sobre a leitura no século XVIII, a partir da análise de romances, dos seus leitores e de sua circulação. Além disso, escreve sobre as novas possibilidades do texto eletrônico e dos novos leitores frente à tela, bem como os novos desafios da escrita (CHARTIER 2009, 2009b, 2007, 2002, 1991). Em seus trabalhos, Chartier apresenta as noções de representação, práticas, apropriação e também questões sobre o texto eletrônico. Dentre os conceitos apresentados pelo autor, serão usados aqui seus diálogos a partir do texto eletrônico e das novas possibilidades de ler e escrever. Estas novas possibilidades modificam também as relações com as provas da história (a nota, a referência, a citação), já que em decorrência do texto eletrônico as mesmas estão sendo colocadas à prova, pois a partir dessa nova maneira de ler, o leitor pode, em partes, percorrer os caminhos do autor:

As citações são fragmentos recortados por mera vontade do historiador, sem possibilidades, para o leitor, de conhecer a totalidade dos textos de onde foram extraídos os fragmentos. Esses três dispositivos clássicos da prova da história (a nota, a referência, a citação) estão muito modificados no mundo da textualidade digital a partir do momento em que o leitor é colocado em posição de poder ler, por sua vez, os livros que o historiador leu e consultar por si mesmo, diretamente, os documentos analisados de produção, organização e certificação dos 
discursos de saber mostram a importância da transformação das operações cognitivas que implica o recurso ao texto eletrônico. (CHARTIER, 2009, p. 60)

No ano de 2004, com a criação da Web $2.0^{13}$, que cria possibilidades para que 0 internauta se torne o produtor de si na rede, convergindo suas identificações do off-line no on-line, observamos a criação dos sites de redes sociais ${ }^{14}$ na Internet (SIBILIA, 2008). O indivíduo, o qual antes se escondia atrás da máscara do nickname, em salas de bate papo

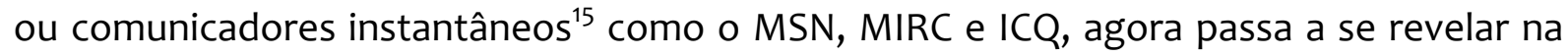
rede colocando os seus dados como nome, profissão, preferência política, religiosa e sexual. .

Ler esse presente faz-se necessário, dando a ele um sentido e transmitindo às novas gerações experiências desse turbilhão de possibilidades que muitas vezes se naturalizam e passam despercebidas. Jean-Pierre Rioux (1999, p. 46) ajuda a problematizar essa questão:

Como não sentir além disso que uma reflexão da história sobre o presente pode ajudar as gerações que crescem a combater a temporalidade contemporânea, a medir o pleno efeito destas fontes originais, sonoras e em imagens, que as mídias fabricam, a relativizar o hino à novidade tão comumente entoado, a se desfazer desse imediatismo vivido que aprisiona a consciência histórica como a folha de plástico "protege" no congelador um alimento que não se consome?

Por mais difícil que seja, tem que se retirar a "folha de plástico que protege" e fazer com que olhemos para os fenômenos do presente ao voltar os olhos para a

13 Desde de 2006 há um conceito de web 3.0, conhecido também como web semântica, publicado em um artigo por John Markoff no The New York Times, que prevê a Internet como um grande catálogo, em que os individuos estarão conectados a todo momento, ao ponto de obterem informações trivais, via busca, tais como melhor escola para os filhos, ou até mesmo conseguir tirar férias com o orçamento reduzido. Até o presente momento, a web 3.0 ainda está no horizonte de expectativa (KOSELLECK, 2006) das grandes corporações.

14 Sites de redes sociais foram definidos por Boyd \& Elison (2007, apud RECUERO, 2009 p.102) como aqueles sistemas que permitem: I) a construção de uma persona através de um perfil ou página pessoal; II) a interação através de comentários; e III) a exposição pública da rede social de cada ator (RECUERO, 2009, p. 102).

15 O MIRC é um comunicador instantâneo, um software de computador que permite o envio e o recebimento de mensagens de texto on-line. Normalmente, esses programas incorporam diversos outros recursos, como o envio de figuras ou imagens animadas, conversação por áudio utilizando as caixas de som e o microfone do sistema, além de videoconferência (por meio de uma webcam). Alguns exemplos de programas: MIRC, MSN, ICQ, Skype, sendo o MIRC um precurssor dessa comunicação instantânea de massa. Cf. Pesquisa sobre o Uso das Tecnologias da Informação e da Comunicação no Brasil: TIC Domicílios e TIC Empresas, 2008. Op. Cit. 
tantas outras abordagens. Como sugere Roger Chartier, "o historiador do tempo presente, por sua capacidade de construir observatórios ajustados às suas preocupações, parece estar em condições de superar os entraves que classicamente limitam a investigação histórica" (CHARTIER, 2006, p. 216). Portanto, o historiador que se lança às pesquisas que envolvem a Internet, e que propõe trabalhá-las como documentos, deve se comprometer com as especificidades que ela traz, como as citadas acima. Não se pode simplesmente transpor metodologias; a forma de se trabalhar com a fonte virtual ainda está por se fazer e é o que caracteriza este trabalho. Tais documentos trazem à cena uma infinidade de abordagens possíveis. Entender a Internet como campo da cultura escrita é uma das possibilidades de análise.

Pode-se pensar que as duas fases da Internet no Brasil, antes e depois de 2004, apresentam níveis de exposição dos internautas variados, nos Comunicadores Instantâneos como o MIRC, e posteriormente com o ICQ, o MSN e o Skype, os níveis de exposição se dão por escolha prévia do usuário, pois ele decide se troca informações ou não no primeiro, e nos seguintes ele elege com quem falar adicionando pessoas que conhece previamente. Já na rede social Orkut, que antecedeu outras formas de interação como MySpace, o Facebook e o Twitter, há uma superexposição dos usuários, com informações diversas. No início do Orkut, por exemplo, havia usuários que concediam telefone e endereço residencial para quem quisesse ver. Já no Facebook e no Twitter, vêse uma superexposição das ações cotidianas, profissionais, construções de si, entre o curtir do primeiro e o retuite do segundo. Este último cumpre o papel de algoz dos blogues, fazendo sombra nas grandes postagens com apenas 140 caracteres.

O tempo das redes sociais e dos comunicadores instantâneos é o tempo cronoscópio, que conta os segundos, os minutos e as horas, essa velocidade que não conta mais com o passado e nem o futuro. O presente na Internet tornou-se uma constante, em que o passado é esquecido rapidamente pela novidade seguinte, como foi o caso do MIRC que, atualmente, é pouco usado devido à gama de redes sociais e 
comunicadores instantâneos que existem e que possibilitam novos recursos, como teleconferência, ou enviar documentos rapidamente. O futuro se torna cada vez mais distante, na espera do novo, do que irá superar. O futuro no tempo do computador é aquele que tornará obsoletos e descartáveis sejam as relações, a moda, as mídias, a leitura, o entretenimento. São todos superados por novos, por mais velozes, mais bonitos, mais tridimensionais, mais reluzentes, mais engraçados, mais atraentes.

O início do século XXI é um acúmulo de vários “mais" que a Internet ajudou a construir deixando um presente superpovoado, cheio de angústias e assolado por uma superexposição para aqueles que têm acesso às redes informatizadas. Por outro lado, no Brasil, há ainda uma parcela muito significativa de pessoas que nem ao menos tem acesso ao saneamento básico, um serviço muito mais essencial para a sociedade, o que leva esses sujeitos a terem outro tipo de relação com o tempo, no qual passam por um processo de inclusão digital sem ao menos terem outros recursos básicos para sobreviverem nesse presentismo desenfreado.

Os livros estão se tornando bits sobre bits nas mãos das grandes corporações, em nome de um acesso global, como é o caso do Google Book Search, site da empresa Google que, conveniado a bibliotecas do mundo do todo, digitaliza seus acervos com a mentalidade de engenheiros, que pensam objetivamente, que não têm a sensibilidade de sentir os cheiros dos livros. Sem contar que a divulgação de acervo global de livros é restrita aos domínios da empresa. Darnton (2010, p. 57) fornece um exemplo dos problemas da digitalização para a História da Cultura e Escrita e da Leitura:

\begin{abstract}
A experiência de ler um pequeno duodécimo, projetado para que o leitor o segure com facilidade com uma única mão, difere consideravelmente da experiência de ler um fólio pesado apoiado num leitoril. É importante poder sentir um livro - a textura do papel, a qualidade da impressão, a natureza da encadernação. Seus aspectos físicos fornecem pistas a respeito de sua existência como elemento num sistema social e econômico; e, se contiver anotações nas margens das páginas, pode revelar muito sobre seu lugar na vida intelectual dos leitores.
\end{abstract}

Que não haja saudosismo para tentar impedir que uma grande corporação mude seus objetivos ao ponto de conservar cada exemplar de um livro específico de uma biblioteca, ao invés de apenas um deles. Mesmo assim, aquilo que se deve ter em mente é que ambas as vias serão beneficiadas; com certeza a maior parte dos benefícios será 
concedida ao Google, que irá cobrar o acesso das obras tabelando um preço por raridade do livro, entretanto, os benefícios para as bibliotecas serão apenas da exposição do seu acervo na Internet. Digitalizar e democratizar não são tarefas fáceis; o que a Empresa Google vem fazendo é se beneficiar de bens públicos em nome de lucros privados, sob a falsa égide do democratizar. Robert Darnton aponta que a solução para este problema não é simples, porém como ele sugere a digitalização de monografias, dissertações e teses, bem como e-books de livros didáticos e paradidáticos, deveriam ser disponíveis gratuitamente on-line e a sua compra, para aqueles que gostam de sentir o papel e o cheiro do livro, seria através da impressão por demanda (DARNTON, 2010, p. 72).

Talvez seja esse o futuro do livro, porém a leitura e sua história tomarão outros rumos, da tela dos (quase) obsoletos computadores e notebooks aos tablets, o tocar na tela será o novo folhear, e quem sabe até o digitar. Será a morte anunciada do teclado? Pois o seu companheiro, o mouse, já está quase em desuso. Nossa interação com a máquina é um jogo de adaptações, um entra e sai de novidades, em que mal dá tempo de se despedir, de se desprender, uma agonia constante.

\section{O Tempo}

Essa problemática vem ao encontro dos pressupostos do Instituto de História do Tempo Presente (IHTP), em que o presente próximo torna-se objeto de estudo para os historiadores a partir dos anos 1970 na França. Esta nova modalidade de estudo vem tentando enfrentar esses problemas do presente, porém não foi a primeira a trabalhar nesta perspectiva. Já foram percebidas estas urgências do presente na primeira geração dos Annales, com Lucien Febvre e Marc Bloch, em 1929, e, desde então, vê-se um crescente nas pesquisas e nas metodologias ancoradas nesta temporalidade. March Bloch afirmava que ““ a análise do presente pode dar a régua e o compasso para a construção da pesquisa histórica” (FEBVRE, 1998 p.47), já o segundo escrevia: “A incompreensão do presente nasce fatalmente da ignorância do passado" (BLOCH, 2001 p.65). Com a criação do IHTP, é vista a emergência dos "retornos" do político, do fato, e dos testemunhos do tempo mais próximo, principalmente os do pós-guerra. O intuito do IHTP estava atrelado à defesa do campo historiográfico, pois em 1963 o jornalista Jean 
Lacouture escreve "A história imediata”, livro que traz um compêndio de pesquisas com recortes temporais próximos (particularmente os anos 1930 e o pós-guerra) (CHAUVEAU e TÉTART, 1999, p. 13). Jean-Pierre Rioux lembra que as vanguardas da História do Tempo Presente, por muito tempo, estavam atreladas aos historiadores do político e coloca as implicações para “Bom senso do artesão":

A história do tempo presente, como vemos, nasceu sem dúvida bem mais de uma impaciência social do que de um imperativo historiográfico, pelo menos na França. E os historiadores do recente, nadando na indolência conceptual assinalada há pouco, mas bastante bem garantidos sobre suas retaguardas sociais, fizeram bonito, no final das contas, martelando o bom senso do velho artesão, metodologicamente pouco sofisticado mas passavelmente percuciente: o argumento da "falta de recuo" não se sustenta, dizem eles, pois é o próprio historiador, desempacotando sua caixa de instrumentos e experimentando suas hipóteses de trabalho, que cria sempre, em todos os lugares e por todo o tempo, o famoso "recuo". (RIOUX, 1999, p. 43)

Assim, pode-se olhar para a História do Tempo Presente como horizonte no qual não há instrumento de referência, tudo está por fazer. Ou seja - como sugere Rioux -, munido de sua caixa de instrumentos, o historiador passa a criar um passado a partir das tecnologias e teorias que lhe asseguram no presente.

É possível pensar a História do Tempo Presente também como uma "história no gerúndio", a qual está em processo de acontecimento/acontecendo, e cabe ao historiador usar dos recursos tecnológicos necessários para construir sua narrativa. Já usamos a tinta e a pena, posteriormente a caneta, a máquina de escrever e, hoje, o computador. Na teoria da história temos exemplos dos embates envolvendo a seleção de documentos na construção das narrativas históricas e, cada qual em seus regimes de historicidades ${ }^{16}$, sofreu por olhar diferente de seus pares: Tucídides com o "ver" contrapondo-se ao "ouvir" de Heródoto (HARTOG, 2003, p. 57), na busca por outra verdade, pois acreditava que a memória era falha; Jules Michelet, o historiador apaixonado pela França, ao contrapor-se à história crônica que, segundo ele, estava fadada ao balbucio, inclui o povo em suas narrativas (DOSSE, 2001, p. 16); Marc Bloch e Lucien Febvre lançando a revista dos Annales em 1929 contrapõem-se aos seus

16 Ao contrário de época, que seria uma forma de seccionar o tempo linear, Hartog (1996) entende os regimes de historicidade como formas de se relacionar com o tempo, pensando nas experiências temporais e nos modos como discorremos sobre o tempo que vivenciamos. 
professores, introduzindo novas maneiras de olhar para o passado: Bloch, com o livro "Os reis taumaturgos" traz as mentalidades para o cerne dessas novas discussões. Novos documentos foram trazidos à tona e, através deles, foi possível olhar para o passado, para além dos documentos ditos “oficiais". Olhar este presente passado faz-se mais do que necessário quando se depara com uma enormidade de fontes que vão se esvaindo com o tempo.

A História do Tempo Presente auxilia a tentar ao menos pensar historicamente estes processos, estas novas formas de conviver e se relacionar. Sevcenko (2001, p. 17), nesse sentido, reflete sobre a aceleração guiada pela montanha russa, nos seguintes termos:

Sendo assim, sentindo-nos incapazes de prever, resistir ou entender o rumo que as coisas tomam, tendemos a adotar a tradicional estratégia de relaxar e gozar. Deixamos para pensar nos prejuízos depois, quando pudermos. Mas o problema é exatamente esse: no ritmo em que as mudanças ocorrem, provavelmente nunca teremos tempo para parar e refletir, nem mesmo para reconhecer o momento em que já for tarde demais. (SEVCENKO, 2001, p. 17)

O estudo até aqui empreendido remete a um cenário virtual marcado pelo dinamismo, pela simultaneidade, pelo acesso variado a informações e, muito especialmente, pela exposição de si com inúmeras possibilidades de (re)inventar-se, seja utilizando recortes de experiências, fotografias e/ou depoimentos personalizados, que conferiram a cada indivíduo, uma dada autoria.

Nesta correria, tentei refletir sobre práticas que com tempo acelerado podem deixar de existir em anos. A Internet possibilitou outras tantas conexões não abordadas aqui. A rede social que proporcionou tantos encontros, hoje na Internet vem perdendo popularidade e usuários para outras tantas redes sociais, principalmente para o Facebook, que oferece um serviço semelhante com poucas alterações para sua funcionalidade. A ascensão e a queda da rede social deu-se em menos de seis anos (2004 a 2010), mostrando a efemeridade da fonte, pois os seus usuários migraram de uma rede social a outras em poucos anos. Esse movimento binário conectar e desconectar aponta para uma aceleração da história através desta agilidade à medida que novos modismos são divulgados na Internet. Assim, coletar estes documentos se faz um desafio, pois os rastros deixados pelos usuários se dissipam junto com o Orkut. A cada perfil 
acelerado que o presente revela. Estas são questões que impulsionaram este trabalho com o intuito de contribuir para pensar sobre as práticas culturais da contemporaneidade em um determinado tempo, espaço e seus protagonistas.

\section{Referências}

ALBUQUERQUE JÚNIOR, Durval Muniz de. História: a arte de inventar o passado - ensaios de teoria da história. Bauru: Edusc, 2007.

BLOCH, Marc. Apologia da história. Rio de Janeiro: Zahar, 2001.

BRESCIANO, Juan Andrés. La historiografía en el amanecer de la cultura digital. Uruguay: Ediciones Cruz del Sur. 2010.

BRIGGS, Asa; BURKE; Peter. Uma história social da mídia: de Gutenberg à Internet. Rio de Janeiro: Zahar, 2006.

GARCÍA CANCLINI, Néstor. A globalização imaginada. São Paulo: Iluminuras, 2003.

CASTELLS, Manuel. A galáxia da Internet: reflexões sobre a Internet, os negócios e a sociedade. Rio de Janeiro: Jorge Zahar, 2003.

CASTILLO GÓMEZ, Antonio. El tiempo de la cultura escrita. A modo de introducción. In: CASTILLO GÓMEZ, Antonio (Coord.) Historia de la cultura escrita. Astúrias, Espanha: Ediciones Trea, 2001.

CHARTIER, Roger. A aventura do livro, do leitor ao navegador: conversações com Jean Lebrun. São Paulo: Impressa Oficial do Estado de São Paulo: Editora UNESP, 2009a.

CHARTIER, Roger. A História ou a leitura do tempo. Belo Horizonte: Autêntica Editora, 2009b.

CHARTIER, Roger. Inscrever e apagar: Cultura Escrita e Literatura - Séculos XI - Século XVIII. São Paulo: Editora Unesp, 2007.

CHARTIER, Roger. O mundo como representação. Estudos Avançados. n.5 p. 173-191. 1991 
CHARTIER, Roger. Os desafios da escrita. São Paulo: Editora UNESP, 2002

CHAUVEAU, Agnès; TÉTART, Philippe (Org). Questões para o presente. Bauru, SP:EDUSC, 1999.

CUNHA, Maria Teresa Santos. Diários Pessoais: territórios abertos para a história. In: PINSKY, Carla Basssnezi; LUCA, Tânia Regina (Orgs.). O historiador e suas fontes. São Paulo: Contexto, 2009. p. 281-308

DARNTON, Robert. A questão dos livros: passado, presente e futuro. São Paulo:

Companhia das Letras, 2010

DOSSE, François. A história à prova do tempo: da história em migalhas ao resgate do sentido. São Paulo: UNESP, 2001

ELIAS, Norbert. O Processo civilizador: volume 2/ formação do Estado e civilização. Rio de janeiro: Zahar Ed.,1993.

FEBVRE, Lucien. Escola dos Annales, São Paulo, Martins Fontes, 1998

GOMES, Ângela Maria de Castro. A escrita de si, escrita da história. Rio de Janeiro: Ed. da FGV, 2004

HANNUD, Alexandre. Wiki In: SPEYR, Juliano (Org.). Para Entender a internet: noções, práticas e desafios da comunicação em rede. Local: Editora, 2009.p.. 57-58

HARTOG, François. Os antigos, o passado e o presente. Brasília: Editora Universidade de Brasília, 2003

HARTOG, François. Regimes de historicidade: time, history and the writimg of history: the Order of Time. In: KVHAA Konferenser Stockholm, 37, 1996. Disponível em <http://www.fflch.usp.br/dh/heros/excerpta/hartog/hartog.html\#*>. Acesso em:11 de abril de 2010.

KOSELLECK, Reinhart. Futuro passado: contribuição à semântica dos tempos históricos. Rio de Janeiro: Contraponto: Ed. PUC - Rio, 2006.

LÉVY, Pierre. Cibercultura. $3^{\text {a }}$ ed. São Paulo: Ed. 34, 2010.

NORA, Pierre. Entre memória e história: a problemática dos lugares. In: Projeto história. São Paulo, nº 10, p. 7-28, dez. 1993.

PESQUISA sobre o uso das tecnologias da informação e da comunicação no Brasil: TIC Domicílios e TIC Empresas, 2008.

RECUERO, Raquel. Redes sociais na Internet. Porto Alegre: Sulina, 2009. 
RIOUX, Jean-Pierre. Pode-se fazer uma história do presente? In: CHAUVEAU, Agnès; Tétart, Philippe (Org). Questões para o presente. Bauru, SP: EDUSC, 1999.

SEVCENKO, Nicolau. A corrida para o século XXI: no loop da montanha-russa. São Paulo: Companhia das Letras, 2001.

SIBÍLIA, Paula. O show do eu: a intimidade como espetáculo. Rio de Janeiro: Nova Fronteira, 2008.

VENANCIO, Giselle. Presente de papel: cultura escrita e sociabilidade na correspondência de Oliveira Vianna. Estudos Históricos. Rio de Janeiro. n. ${ }^{\circ}$ 28, p.23-47, 2001. 